LICENÇA CC BY:

Artigo distribuído sob os termos

Creative Commons, permite uso e distribuição irrestrita em qualquer meio desde que o autor credite a fonte original.

\section{O PENSAMENTO COMPUTACIONAL NA FORMAÇÃO DO LICENCIANDO EM PEDAGOGIA}

COMPUTATIONAL THINKING IN THE FORMATION OF THE LICENTIATE IN PEDAGOGY PENSAMIENTO COMPUTACIONAL EN LA FORMACIÓN DE LICENCIADOS EN PEDAGOGIA

Valdir José Corrêa Júnior ${ }^{1}$ André Luis Alice Raabe ${ }^{1}$

'Programa de Pós-Graduação em Educação, Universidade do Vale do Itajaí, Itajaí, SC, Brasil.

Aprovado em: 11/03/2020

Resumo: Este artigo é parte de uma tese de doutorado em andamento, na qual se defende a importância de se promover a inserção do Pensamento Computacional nos cursos de Licenciatura em Pedagogia, dado que este se faz presente na Base Nacional Comum Curricular (BNCC) e esta, por sua vez, a partir da Resolução 02/2019 do Conselho Nacional de Educação, constitui-se no elemento norteador dos currículos de formação dos professores da Educação Básica. Trata-se de uma pesquisa de abordagem qualitativa e, quanto à sua tipologia, constitui-se como empírica (Estudo de (aso) e documental, tendo como método a análise de conteúdo. As evidências obtidas por meio de uma intervenção junto a licenciandos do curso de Pedagogia da Universidade do Vale do Itajaí, por meio de oficinas pedagógicas, indicam que é possível e viável a proposição de atividades com o objetivo de desenvolver o Pensamento Computacional para este público.

Palavras-chave: Pensamento Computacional; Base Nacional Comum Curricular; Formação de Professores.

Abstract: This article is part of an ongoing doctoral thesis that defends the importance of promoting the insertion of Computational Thinking in the Licentiate course in Pedagogy, as it is present in the National Common Curricular Base (Base Nacional Comum Curricular (BNCC)) and this, in turn, based on Resolution 02/2019 of the National Council of Education, constitutes the guiding element of the curricula for training Basic Education teachers. This research uses a qualitative approach. In terms of typology, it is empirical (a case Study) and documental, using content analysis as a method. The evidence obtained through an intervention with graduate students of the Pedagogy course at the University of Vale do Itajaí, through pedagogical 
workshops, indicate that it is possible and viable to propose activities aimed at developing Computational Thinking for this public.

Keywords: Computational Thinking; Common National Curricular Base; Teacher training.

Resumen: Este artículo es parte de una tesis doctoral en curso, en la que se defiende la importancia de promocionar la inserción del Pensamiento Computacional en los cursos de Licenciatura en Pedagogía, dado que está presente en la Base Curricular Común Nacional y esta, a su vez, a partir de la Resolución 02/2019 del Consejo Nacional de Educación, constituye el elemento rector de los planes de estudio para la formación de docentes de Educación Básica. Esta es una investigación con un enfoque cualitativo $y$, en cuanto a su tipología, se constituye como empírica (Estudio de caso) y documental, utilizando el análisis de contenido como método. La evidencia obtenida a través de una intervención con graduados del curso de Pedagogía en la Universidad del Vale do Itajaí, a través de talleres pedagógicos, indica que es posible y viable proponer actividades con el objetivo de desarrollar el Pensamiento Computacional para este público.

Palabras clave: Pensamiento computacional; Base Curricular Nacional Común; Formación de profesores.

\section{Introdução}

Diferentes aspectos de nossa sociedade têm sido influenciados pelas tecnologias digitais. Esta constatação dá-se quando analisamos a forma como nos relacionamos nas diversas redes sociais, a maneira como se dá a busca e o acesso a informações, como estruturamos o comércio, etc. Parte da nossa sociedade já está inserida na cultura digital (VALENTE, 2016). Entretanto, parte significativa desta inserção é realizada de forma a subutilizar o potencial dessas tecnologias, uma vez que as utilizamos como "softwares de escritório"; ainda não conseguimos explorá-las em todas as suas possibilidades: elas constituem-se, ainda, em poderosas máquinas de escrever, de pesquisa e de comunicação. Diante deste cenário, Valente (2016, p. 866) aponta um caminho ao afirmar que:

Certamente as TDIC $^{1}$ podem oferecer muito mais. Para tanto, será necessário aprofundarmos nossa concepção sobre essas tecnologias, entendendo como elas funcionam, como elas podem ser adaptadas aos diferentes contextos e situações de nosso dia a dia e, com isso, podermos usufruir dos verdadeiros benefícios da cultura digital. (VALENTE, 2016, p. 866).

Diversos estudos na área da Educação têm sido realizados ao redor do mundo mostrando que um melhor uso dessas tecnologias digitais está relacionado à disseminação de ideias até então restritas à área da Computação e enfatizando a importância da programação para todos. Exemplo disso foi a ação promovida pela Casa Branca (EUA, 2013), sob o título de Computer Science is for Everyone! (A Ciência da Computação é para todos!), que faz um convite aos envolvidos nos processos educativos nos EUA a investirem na programação, indicando diversos benefícios que ela pode trazer, tanto acadêmicos, como cognitivos e para o mercado de trabalho. Esta referência aos conceitos da Ciência da Computação está baseada no argumento de que as atividades promovidas ao longo dos estudos dessa ciência permitem o desenvolvimento do 
pensamento crítico e computacional, além de possibilitar o empoderamento dos estudantes no sentido de serem criadores "de" e "a partir" das tecnologias e não meros consumidores de "softwares de escritório". Para Conforto (2018, p. 100), o desenvolvimento destas formas de pensar se constituem em atributos fundamentais para o século XXI:

O conjunto de capacidades cognitivas para ler, escrever e fazer operações matemáticas, que foi fundamental para o exercício da cidadania até o século passado, necessita ser ampliado, acrescido da habilidade do pensamento computacional, essa capacidade de descrever, de explicar, de operar com situações complexas. As concepções quanto à alfabetização e ao letramento digital têm sido ampliadas radicalmente. Dos processos de instrumentalização para o uso de recursos computacionais, passa-se à necessidade de desenvolver as habilidades exigidas para atuar na sociedade do século XXI, em especial, utilizar saberes e dispositivos tecnológicos para construir respostas a problemas. (CONFORTO et al., 2018, p. 100).

Argumentos como estes têm feito com que muitos países realizem transformações em seus currículos, a fim de incluir elementos da Ciência da Computação e, em particular, - Pensamento Computacional nas escolas, em alguns casos, desde os primeiros anos da Educação Básica. Grécia e Estônia são exemplos de países que incluíram a programação no conjunto das disciplinas obrigatórias, desde o Ensino Infantil até o equivalente ao nono ano em nosso modelo educacional. Embora em alguns países a ênfase esteja sendo dada à inserção da programação por meio de atividades que promovam o desenvolvimento do Pensamento Computacional, outros países, como a Itália, buscam ir além do programar para explorar os conceitos computacionais e desenvolver o Pensamento Computacional, abordando o tema de forma não disciplinar, buscando incorporá-lo ao currículo de forma transversal (VALENTE, 2016). Mas o que é o Pensamento Computacional?

Cientistas da computação e outros pesquisadores que se dedicam a estudar o tema ainda não chegaram a um consenso sobre a definição de Pensamento Computacional. Esta expressão ganhou força no cenário acadêmico em 2006, quando, num artigo, a pesquisadora Jeannette M. Wing afirma que o "pensamento computacional se baseia no poder e nos limites de processos de computação, quer eles sejam executados por um ser humano ou por uma máquina" (WING, 2006, p. 33). A International Society for Technology in Education - ISTE afirma que Pensamento Computacional consiste em "desenvolver e empregar estratégias para entender e resolver problemas de forma a aproveitar o poder dos métodos tecnológicos para desenvolver e testar soluções". Liukas (2015) salienta que "o Pensamento Computacional é executado por pessoas e não por computadores. Ele inclui o pensamento lógico, a habilidade de reconhecimento de padrões, raciocinar através de algoritmos, decompor e abstrair um problema" (LIUKAS, 2015). Zapata-Ros (2015, p. 13) descreve um conjunto de componentes do Pensamento Computacional, tais como criatividade, resolução de problemas, pensamento abstrato, interação, metacognição, dentre outros.

A percepção da importância de se trazer o Pensamento Computacional para a Educação Básica vem ganhando força no Brasil. Estudos vêm sendo realizados com alunos das mais 
diferentes etapas da Educação Básica e os resultados são animadores. Raabe et al. (2015) sinalizam para o fato de que:

No Brasil, iniciativas de introdução ao Pensamento Computacional têm sido multiplicadas a cada ano e publicadas nos veículos da Comissão especial de Informática na Educação da SBC e também no Workshop de Educação em Computação. Muitas apontam resultados promissores relacionados ao engajamento dos estudantes e o potencial de interdisciplinaridade envolvida. Este cenário, impulsionado também por iniciativas de empresas e de outros países, em especial os Estados Unidos da América, tem tornado a possibilidade de inserção de conhecimentos relativos à computação como candidatos e serem aderidos pela Educação Básica. (RAABE, 2015).

Há, porém, alguns aspectos que ainda estão sendo estudados e que impactam diretamente no processo de introdução do Pensamento Computacional na Educação Básica: o primeiro está relacionado a como avaliar o desenvolvimento do Pensamento Computacional nos alunos; e o segundo, mais diretamente relacionado ao objeto de estudo nesta pesquisa, está relacionado à formação de professores para desenvolver atividades que promovam o Pensamento Computacional. Em relação a este segundo aspecto, a formação de professores, consideramos particularmente importante o estudo desenvolvido por Yadav et al. $(2011,2014)$. Nele, os pesquisadores inseriram um módulo sobre Pensamento Computacional em um curso obrigatório para a formação de professores para a Educação Básica da Purdue University, curso este denominado "Aprendizagem e Motivação". Além de apresentar aos participantes do curso conceitos da Ciência da Computação, o módulo tinha como objetivo fazê-los perceber que esses conceitos poderiam ser utilizados quando eles estivessem desenvolvendo seu trabalho em sala de aula. Após processo avaliativo, os pesquisadores chegaram à conclusão de que este módulo ajudou os participantes a:

Entenderem que podem ensinar conceitos de Ciência da Computação nas salas de aula, sem o uso de computadores e

Conceitos sobre o Pensamento Computacional podem ser incorporados em todas as disciplinas.

Quanto à primeira conclusão, é importante ressaltar a constatação incomum, podemos assim dizer, de se desenvolver conceitos da Ciência da Computação sem o uso de computadores², o que, para um país com enormes carências e dificuldades como o Brasil, constitui-se em uma oportunidade de proporcionar situações pedagógicas que promovam o desenvolvimento do Pensamento Computacional nos mais diversos contextos e realidades. A segunda conclusão, por sua vez, apresenta a possibilidade de um trabalho interdisciplinar, não cabendo a apenas um professor ou a uma disciplina o desenvolvimento desses conceitos. De toda forma, ambas estão relacionadas diretamente à formação do professor.

A Base Nacional Comum Curricular - BNCC - faz referência explícita ao Pensamento Computacional e à necessidade de desenvolvê-lo:

Os processos matemáticos de resolução de problemas, investigação [...]. Esses processos de aprendizagem são potencialmente ricos para o desenvolvimento de competências 
fundamentais para o letramento matemático e para o desenvolvimento do pensamento computacional. (BNCC, Ensino Fundamental, p.264, grifo nosso).

Mas a quem cabe promover situações de aprendizagem e desenvolvimento do pensamento dos alunos? Cabe ao professor, sem dúvidas. Mas para que ele possa realizar esta tarefa, ele mesmo precisa ter desenvolvido estas competências. Segundo Mello:

\begin{abstract}
[...] Ninguém facilita o desenvolvimento daquilo que não teve oportunidade de aprimorar em si mesmo. Ninguém promove a aprendizagem de conteúdos que não domina, a constituição de significados que não compreende nem a autonomia que não pôde construir. É imprescindível que o professor que se prepara para lecionar na educação básica demonstre que desenvolveu ou tenha oportunidade de desenvolver, de modo sólido e pleno, as competências previstas para os egressos da educação básica [...]. (MELLO, 2000, p. 102).
\end{abstract}

Ora, se a Base Nacional Comum Curricular será o fundamento para a construção dos currículos para formação de professores e ela traz em diferentes momentos, referências ao uso das tecnologias digitais e ao Pensamento Computacional, a qual etapa da Educação Básica cabe a tarefa de trazer tais elementos para o contexto da sala de aula?

Uma leitura atenta da BNCC pode indicar uma possível resposta para esta pergunta. Nela encontramos inúmeras vezes referências às tecnologias digitais desde a etapa do Ensino Fundamental Anos Iniciais - EFAI. Importante: estas referências aparecem em praticamente todas as áreas do conhecimento. E, quando menciona tais tecnologias digitais, o contexto é sempre da criação, do uso crítico, do desenvolvimento da imaginação, ou seja, convergindo para atributos do Pensamento Computacional. Postulamos, aqui, que há uma relação umbilical entre o uso das tecnologias digitais conforme estabelecido na BNCC e o desenvolvimento do Pensamento Computacional, de tal forma que, ao utilizá-las, desenvolve-se o Pensamento Computacional e, ao desenvolvê-lo, amplia-se o poder de pensar e agir com e a partir destas tecnologias, gerando assim um círculo virtuoso. Se, na Base Nacional Comum Curricular do Ensino Fundamental, Anos Iniciais - BNCC/EFAI -, as referências às tecnologias digitais são explícitas, o mesmo não ocorre com o Pensamento Computacional: ele é apresentado de maneira indireta, por meio de seus elementos constituintes, seus pilares. Assim, por exemplo, no $1^{\circ}$ ano do Ensino Fundamental, a habilidade dez, para a área de Matemática, "descrever, após o reconhecimento e a explicitação de um padrão (ou regularidade), os elementos ausentes em sequências recursivas de números naturais, objetos ou figuras" está diretamente relacionada à percepção de padrões, um dos quatro pilares do Pensamento Computacional.

Assim, diante de tudo o que foi exposto, acreditamos ser fundamental que se oportunizem aos futuros professores da Educação Básica, ainda em sua formação inicial, e em particular aos professores do Ensino Fundamental - Anos Iniciais, condições para que desenvolvam o Pensamento Computacional e, consequentemente, que possam potencializar o uso das tecnologias digitais disponíveis em sua prática, assim como ocorre com Matemática, Língua Portuguesa, História, Geografia, Ciências, cujo estudo tem início logo nos primeiros anos da Educação Básica. 


\section{Pensamento Computacional}

O Pensamento Computacional é uma competência humana! Um equívoco frequente quando se trata do Pensamento Computacional é o de entendê-lo como sendo alguma competência relacionada ao uso de softwares. Valente $(2016$, p. 866) esclarece que o surgimento dos editores de textos, de imagens, planilhas eletrônicas, dentre outros, contribuiu para que as novas tecnologias fossem inseridas no contexto educacional, mas quase nada trouxeram de avanços se analisadas sob a perspectiva de serem agentes promotores do desenvolvimento do pensamento lógico dos alunos.

Apesar de Papert, já na década de 1970, ter apontado que a programação de computadores poderia servir de forma inovadora para a construção e para o desenvolvimento do pensamento, impactando de forma significativa a elaboração de conceitos por parte dos alunos em diversas áreas do conhecimento, notadamente, mas não exclusivamente, na Matemática e na Lógica (PAPERT, 1971), o termo Pensamento Computacional despontou no cenário acadêmico em 2006, por ocasião da publicação de um artigo redigido por Jeannett Marie Wing. O que escreveu Wing?

Já no primeiro parágrafo, Wing estabelece as bases para o que entende por Pensamento Computacional, ao sugerir que "o Pensamento Computacional baseia-se no poder e nas limitações dos processos computacionais, independentemente de quem os executa, seja um ser humano ou uma máquina" (WING, 2006 p. 33). Na sequência, apresenta o pensamento computacional como uma competência indispensável para a formação do sujeito do século 21, colocando-o no mesmo patamar que a competência leitora, escritora e matemática (WING, 2006). Este aspecto é muito importante, uma vez que as atividades humanas estão cada vez mais envoltas pelas tecnologias e estas, por sua vez, relacionam-se umbilicalmente com a Ciência da Computação.

Depois de Wing, vários outros autores e pesquisadores propuseram definições para o Pensamento Computacional, mas não se pode afirmar que chegaram a uma definição mundialmente aceita. Para Blikstein (2008):

Pensamento computacional é saber usar o computador como um instrumento de aumento do poder cognitivo e operacional humano - em outras palavras, usar computadores, e rede de computadores, para aumentar nossa produtividade, inventividade e criatividade. (BLIKSTEIN, 2008).

A International Society for Technology in Education (CSTA, ISTE, 2011), juntamente com a Computer Science Teachers Association (CSTA), a partir da análise das competências que os estudantes devem ter ao finalizarem a High School (correspondente ao Ensino Médio, no Brasil), definem o Pensamento Computacional como sendo um processo de resolução de problemas que inclui, mas não é limitada por, as seguintes características: coleta de dados, análise de dados, representação de dados, decomposição de problemas, abstração, algoritmos 
e procedimentos, automação, paralelização e simulação.

Selby e Woollard (2012) propuseram uma definição para o Pensamento Computacional associada às principais habilidades baseada em uma revisão de literatura. Para eles, o Pensamento Computacional é um processo cognitivo que reflete as habilidades de pensar de forma abstrata e algorítmica, saber decompor atividades complexas, bem como realizar avaliações e generalizações.

Por sua vez, Barcelos e Silveira (2012, p. 9-10) propõem que:

O pensamento computacional define competências e habilidades que se tornam fundamentais para o efetivo domínio da tecnologia por todos em um mundo em que os dispositivos computacionais são cada vez mais pervasivos. Incorporar o pensamento computacional à educação básica envolve a análise sistemática de sua potencial sinergia com outras áreas do conhecimento, como a Matemática. (BARCELOS; SILVEIRA, 2012, p. 9 - 10).

Segundo Mestre et al. (2015, p.1281), o Pensamento Computacional estimula o desenvolvimento de habilidades relacionadas à resolução de problemas, envolvendo a capacidade de ler, interpretar textos, representar situações por meio de modelos matemáticos, científicos ou sociais.

Bundy (2007, p. 67) percebe que "o Pensamento Computacional está influenciando a pesquisa em quase todas as disciplinas [...]. A Computação permitiu que pesquisadores perguntassem novos tipos de perguntas e aceitassem novos tipos de respostas, por exemplo, questões que exigem o processamento de enormes quantidades de dados." (BUNDY, 2007). Neste sentido, o Pensamento Computacional é visto como um conjunto de habilidades utilizadas na construção de programas computacionais para resolver problemas específicos das diferentes áreas.

Outro conceito de Pensamento Computacional a ser abordado é o dado pela Royal Society (2012, p. 29):

O Pensamento Computacional é o processo de reconhecer os aspectos da computação no mundo que nos rodeia e aplicar as ferramentas e técnicas da Ciência da Computação para entender e raciocinar sobre os sistemas e processos naturais e artificiais. Mais uma vez temos a preocupação de trazer a Ciência da Computação para fora dos laboratórios. A Royal Society acredita que já estamos rodeados de conceitos relacionados à Ciência da Computação e que cabe a nós reconhecê-los. (ROYAL SOCIETY , 2012, p. 29).

Segundo a British Broadcasting Corporation - BBC (2020),

O pensamento computacional nos permite pegar um problema complexo, entender qual é o problema e desenvolver possíveis soluções. Podemos então apresentar essas soluções de uma maneira que um computador, um humano ou ambos, possam entender. (BBC, 2020). 
Outros vários autores apresentam definições distintas para o que seria Pensamento Computacional. Se não há ainda uma definição universalmente aceita, há a certeza do que Pensamento Computacional não é: saber navegar na internet, acessar e-mails, editar um texto, utilizar planilhas eletrônicas, elaborar uma apresentação ou manipular um equipamento eletrônico. Tentar reduzi-lo a isso é retirar seu poder criativo e inovador.

Brackmann (2017, p. 32) apresenta os "pilares" do Pensamento Computacional:

Pesquisas lideradas por Code.org (2016), Liukas (2015) e BBC.Learning (2015) mesclaram os elementos citados por Grover e Pea (2013) e o guia difundido por Computer at School (CIZMADA et al., 2015) e resumiram nos chamados "Quatro Pilares do Pensamento Computacional", sendo eles: Decomposição, Reconhecimento de Padrões, Abstração e Algoritmos. (BRACKMANN, 2017, p. 32).

A BBC (2020) apresenta uma definição suscinta de cada um destes pilares:

decomposição - decompor um problema ou sistema complexo em partes menores e mais gerenciáveis;

reconhecimento de padrões - procurando semelhanças entre e dentro dos problemas;

abstração - concentrando-se apenas nas informações importantes, ignorando detalhes irrelevantes;

algoritmos - desenvolvendo uma solução passo a passo para o problema ou as regras a seguir para resolvê-lo.

"Pensar computacionalmente" (utilizar o Pensamento Computacional) implica em fazer uso destes "pilares" para amplificar a capacidade humana de resolver problemas.

\section{Pensamento Computacional na Base Nacional Comum Curricular}

Muitos países (Estados Unidos, Austrália, Lituânia, dentre outros), com o intuito de oferecer um processo educacional mais qualificado, significativo e sintonizado às necessidades do século XXI, não estão hesitando em modificar seus currículos, inserindo o Pensamento Computacional ou a Ciência da Computação em suas escolas de Educação Básica. No Brasil, a tecnologia na educação, como política pública, vem sendo historicamente tratada sob a égide do letramento digital e/ou da inclusão digital. O número de estudos acerca da introdução do Pensamento Computacional nas escolas tem crescido ao longo dos anos, mas o país ainda está "engatinhando" neste aspecto. Os estudos indicam que o uso pedagógico da robótica, da programação em softwares como o Scratch, da construção de jogos digitais e de aplicativos computacionais podem ser elementos importantes para a percepção da importância do Pensamento Computacional na escola, mas, como já dito, as experiências são incipientes. Importante destacar que algumas instituições, como o Colégio de Aplicação da UNIVALI (Itajaí, SC), já incorporaram o Pensamento Computacional como disciplina em seus currículos. 
Além disso, diversos projetos têm sido desenvolvidos através, mas não apenas, do Laboratório de Inovação Tecnológica na Educação - LITE - (UNIVALI). Dentre eles, destaca-se o Robô Programável Educacional (RoPE), que vem sendo utilizado com sucesso em diversas escolas da rede pública de diversos municípios da região do Vale do Itajaí.

Raabe et al. (2015) alertam para o fato de que:

No Brasil, iniciativas de introdução ao Pensamento Computacional têm sido multiplicadas a cada ano e publicadas nos veículos da Comissão especial de Informática na Educação da SBC e também no Workshop de Educação em Computação. Muitas apontam resultados promissores relacionados ao engajamento dos estudantes e o potencial de interdisciplinaridade envolvida. Este cenário, impulsionado também por iniciativas de empresas e de outros países, em especial os Estados Unidos da América, tem tornado a possibilidade de inserção de conhecimentos relativos à computação como candidatos e serem aderidos pela Educação Básica. (RAABE, 2015).

Nessa mesma perspectiva, França e Tedesco (2015) defendem a inserção do Pensamento Computacional desde a Educação Básica como forma de melhorar o aprendizado lógico em nível escolar dos alunos e possibilitar o uso mais eficaz dessas tecnologias móveis em benefício da sociedade.

A Base Nacional Comum Curricular - BNCC - para o Ensino Fundamental, mesmo diante das controvérsias nas quais está envolta, incorporou o tema "tecnologia" ao currículo desta etapa da Educação Básica.

A BNCC divide as competências em três categorias hierarquizadas: as competências gerais, em número de dez; as competências específicas das áreas do conhecimento; e as competências específicas dos componentes curriculares. As competências gerais afetam todas as ações pedagógicas a serem desenvolvidas na escola (ou em outros espaços educativos). Dentro das competências gerais, três tratam do uso e da produção de tecnologia.

Segundo o Centro de Inovação para Educação Brasileira - CIEB:

A presença da tecnologia nas competências gerais da Base influencia a interpretação das instâncias inferiores do documento: as áreas do conhecimento e os componentes curriculares. Ainda assim, estes elementos também fazem suas próprias menções ao tema nas competências específicas (das áreas e de cada componente), bem como nos objetos do conhecimento e habilidades. (CIEB, 2018 p. 12).

Particularmente para a etapa do Ensino Fundamental, área de atuação dos sujeitos que fazem parte deste estudo, a BNCC faz referência às tecnologias digitais nas diferentes áreas do conhecimento. Na sequência do texto, indicar-se-á a presença de termos relacionados ao Pensamento Computacional ou às tecnologias digitais nessas áreas.

Na área da Matemática, a BNCC refere-se explicitamente ao Pensamento Computacional:

Os processos matemáticos de resolução de problemas, investigação [...]. Esses processos de aprendizagem são potencialmente ricos para o desenvolvimento de competências fundamentais para o letramento matemático e para o desenvolvimento do pensamento computacional. (BNCC, Ensino Fundamental, p.264, grifo nosso). 
Dentro das competências específicas para a área da Matemática, em diferentes momentos a BNCC utiliza a expressão tecnologia digital ou faz uso de termos associados ao Pensamento Computacional:

Enfrentar situações problemas [...] além do texto escrito na língua materna e outras linguagens para representar algoritmos [...]. (BNCC, Ensino Fundamental, p.265, grifo nosso).

O Quadro 1 apresenta as habilidades específicas da área de Matemática para os Anos Iniciais do Ensino Fundamental, nas quais há referência a termos associados ao Pensamento Computacional e à expressão tecnologias digitais.

Quadro 1 - Pensamento Computacional e tecnologias digitais na área de Matemática (BNCC)

\begin{tabular}{|c|c|c|}
\hline ANO & $\mathrm{HAB}$ & DESCRIÇÃO \\
\hline $1^{\circ}$ & 10 & $\begin{array}{l}\text { Descrever, após o reconhecimento e a explicitação de um padrão (ou regularidade), os } \\
\text { elementos ausentes em sequências recursivas de números naturais, objetos ou figuras. }\end{array}$ \\
\hline $2^{\circ}$ & 09 & $\begin{array}{l}\text { Construir sequências de números naturais em ordem crescente ou decrescente a partir de } \\
\text { um número qualquer, utilizando uma regularidade estabelecida. }\end{array}$ \\
\hline $2^{\circ}$ & 10 & $\begin{array}{l}\text { Descrever um padrão (ou regularidade) de sequências repetitivas e de sequências recursi- } \\
\qquad \text { vas por meio de palavras, símbolos e desenhos. }\end{array}$ \\
\hline $3^{\circ}$ & 10 & $\begin{array}{l}\text { Identificar regularidades em sequências ordenadas de números naturais, resultantes da } \\
\text { realização de adições ou subtrações sucessivas por um mesmo número, descrever uma regra } \\
\text { de formação da sequência e determinar elementos faltantes ou seguintes. }\end{array}$ \\
\hline $3^{\circ}$ & 16 & $\begin{array}{c}\text { Reconhecer figuras congruentes, usando sobreposição e desenhos em malhas quadriculadas } \\
\text { ou triangulares, incluindo o uso de tecnologias digitais. }\end{array}$ \\
\hline $4^{\circ}$ & 03 & $\begin{array}{l}\text { Resolver e elaborar problemas com números naturais envolvendo adição e subtração, } \\
\text { utilizando estratégias diversas, como cálculo, cálculo mental e algoritmos, além de fazer } \\
\text { estimativas do resultado. }\end{array}$ \\
\hline $4^{\circ}$ & 07 & $\begin{array}{l}\text { Resolver e elaborar problemas de divisão cujo divisor tenha no máximo dois algarismos, } \\
\text { envolvendo os significados de repartição equitativa e de medida, utilizando estratégias } \\
\text { diversas, como cálculo por estimativa, cálculo mental e algoritmos. }\end{array}$ \\
\hline $4^{\circ}$ & 11 & $\begin{array}{c}\text { Identificar regularidades em sequências numéricas compostas por múltiplos de um número } \\
\text { natural. }\end{array}$ \\
\hline $4^{\circ}$ & 28 & $\begin{array}{l}\text { Realizar pesquisa envolvendo variáveis categóricas e numéricas e organizar dados coletados } \\
\text { por meio de tabelas e gráficos de colunas simples ou agrupadas, com e sem uso de tecno- } \\
\text { logias digitais. }\end{array}$ \\
\hline $5^{\circ}$ & 07 & $\begin{array}{l}\text { Resolver e elaborar problemas de adição e subtração com números naturais e com números } \\
\text { racionais, cuja representação decimal seja finita, utilizando estratégias diversas, como cálculo } \\
\text { por estimativa, cálculo mental e algoritmos. }\end{array}$ \\
\hline $5^{\circ}$ & 08 & $\begin{array}{l}\text { Resolver e elaborar problemas de multiplicação e divisão com números naturais e com } \\
\text { números racionais, cuja representação decimal é finita (com multiplicador natural e divisor } \\
\text { natural e diferente de zero), utilizando estratégias diversas, como cálculo por estimativa, } \\
\text { cálculo mental e algoritmos. }\end{array}$ \\
\hline
\end{tabular}




\begin{tabular}{|c|c|c|}
\hline $5^{\circ}$ & 17 & $\begin{array}{r}\text { Reconhecer, nomear e comparar polígonos, considerando lados, vértices e ângulos, e } \\
\text { desenhá-los, utilizando material de desenho ou tecnologias digitais. }\end{array}$ \\
\hline $5^{\circ}$ & 18 & $\begin{array}{r}\text { Reconhecer a congruência dos ângulos e a proporcionalidade entre os lados correspond- } \\
\text { entes de figuras poligonais em situações de ampliação e de redução em malhas quadricula- } \\
\text { das e usando tecnologias digitais. }\end{array}$ \\
\hline $5^{\circ}$ & 25 & $\begin{array}{r}\text { Realizar pesquisa envolvendo variáveis categóricas e numéricas, organizar dados coletados } \\
\text { por meio de tabelas, gráficos de colunas, pictóricos e de linhas, com e sem uso de tecno- } \\
\text { logias digitais, e apresentar texto escrito sobre a finalidade da pesquisa e a síntese dos } \\
\text { resultados. }\end{array}$ \\
\hline
\end{tabular}

Fonte: Elaborado pelo Pesquisador.

$\mathrm{Na}$ área de Linguagens, faz-se referência à linguagem digital nas competências específicas quando se estabelece que:

Utilizar diferentes linguagens - verbal (oral ou visual-motora, como Libras, e escrita), corporal, visual, sonora e digital -, para se expressar e partilhar informações, experiências, ideias e sentimentos em diferentes contextos e produzir sentidos que levem ao diálogo, à resolução de conflitos e à cooperação. (BNCC, Ensino Fundamental, p. 63).

\section{O componente Língua Portuguesa da BNCC:}

(...) dialoga com documentos e orientações curriculares produzidos nas últimas décadas, buscando atualizá-los em relação às pesquisas recentes da área e às transformações das práticas de linguagem ocorridas neste século, devidas em grande parte ao desenvolvimento das tecnologias digitais da informação e comunicação (TDIC). (BNCC, Ensino Fundamental, p. 65).

Dentro das competências específicas para este componente, tem-se que:

Mobilizar práticas da cultura digital, diferentes linguagens, mídias e ferramentas digitais para expandir as formas de produzir sentidos (nos processos de compreensão e produção), aprender e refletir sobre o mundo e realizar diferentes projetos autorais. (BNCC, Ensino Fundamental, p.87).

Ainda na área das Linguagens, no componente Artes, que aparece centrado em quatro unidades temáticas: Artes Visuais, Dança, Música e Teatro, encontramos uma última unidade, Artes Integradas, que explora as relações e as articulações entre as diferentes linguagens e suas práticas, inclusive aquelas possibilitadas pelo uso das novas tecnologias de informação e comunicação.

No componente Educação Física não há competências específicas que apresentem relação com o Pensamento Computacional e/ou referências às tecnologias digitais.

O Quadro 2 apresenta as habilidades relativas a cada um dos componentes da área de Linguagens para o Ensino Fundamental, Anos Iniciais ( $1^{\circ}$ ao $5^{\circ}$ ano), as quais mantêm relação com elementos do Pensamento Computacional ou que fazem referência às tecnologias digitais 
Quadro 2 - Pensamento Computacional e tecnologias digitais na área de Linguagens (BNCC)

\begin{tabular}{|c|c|}
\hline COMPONENTE & HABILIDADE \\
\hline LINGUA PORTUGUESA ${ }^{3}$ & $\begin{array}{l}\text { (EF15LP01) Identificar a função social de textos que circulam em campos da vida } \\
\text { social dos quais participa cotidianamente (a casa, a rua, a comunidade, a escola) e } \\
\text { nas mídias impressa, de massa e digital, reconhecendo para que foram produzidos, } \\
\text { onde circulam, quem os produziu e a quem se destinam. } \\
\text { (EF15LP05) Planejar, com a ajuda do professor, o texto que será produzido, con- } \\
\text { siderando a situação comunicativa, os interlocutores (quem escreve/para quem es- } \\
\text { creve); a finalidade ou o propósito (escrever para quê); a circulação (onde o texto vai } \\
\text { circular); o suporte (qual é o portador do texto); a linguagem, organização e forma } \\
\text { do texto e seu tema, pesquisando em meios impressos ou digitais, sempre que for } \\
\text { preciso, informações necessárias à produção do texto, organizando em tópicos os } \\
\text { dados e as fontes pesquisadas. } \\
\text { (EF15LP08) Utilizar software, inclusive programas de edição de texto, para editar e } \\
\text { publicar os textos produzidos, explorando os recursos multissemióticos disponíveis. } \\
\text { (EF12LP04) Ler e compreender, em colaboração com os colegas e com a ajuda do } \\
\text { professor ou já com certa autonomia, listas, agendas, calendários, avisos, convites, } \\
\text { receitas, instruções de montagem (digitais ou impressos), dentre outros gêneros do } \\
\text { campo da vida cotidiana, considerando a situação comunicativa e o tema/assunto } \\
\text { do texto e relacionando sua forma de organização à sua finalidade. } \\
\text { (EF12LP06) Planejar e produzir, em colaboração com os colegas e com a ajuda do } \\
\text { professor, recados, avisos, convites, receitas, instruções de montagem, dentre outros } \\
\text { gêneros do campo da vida cotidiana, que possam ser repassados oralmente por } \\
\text { meio de ferramentas digitais, em áudio ou vídeo, considerando a situação comuni- } \\
\text { cativa e o tema/assunto/finalidade do texto. } \\
\text { (EF02LP21) Explorar, com a mediação do professor, textos informativos de diferentes } \\
\text { ambientes digitais de pesquisa, conhecendo suas possibilidades. }\end{array}$ \\
\hline ARTES & $\begin{array}{l}\text { (EF15AR26) Explorar diferentes tecnologias e recursos digitais (multimeios, ani- } \\
\text { mações, jogos eletrônicos, gravações em áudio e vídeo, fotografia, softwares, etc.) } \\
\text { nos processos de criação artística. }\end{array}$ \\
\hline EDUCAÇÃO FÍSICA & Nenhuma referência. \\
\hline
\end{tabular}

Fonte: Elaborado pelo Pesquisador.

$\mathrm{Na}$ área de Ciências da Natureza há referência ao letramento científico, o qual envolve "a capacidade de compreender e interpretar o mundo (natural, social e tecnológico)" (BNCC, Ensino Fundamental, p.319). Segundo a BNCC (Ensino Fundamental, p.321), o ensino de Ciências deve, dentre outros, promover situações para que os alunos possam:

Desenvolver e utilizar ferramentas, inclusive digitais, para coleta, análise e representação de dados (imagens, esquemas, tabelas, gráficos, quadros, diagramas, mapas, modelos, representações de sistemas, fluxogramas, mapas conceituais, simulações, aplicativos, etc.) e 
Desenvolver soluções para problemas cotidianos usando diferentes ferramentas, inclusive digitais.

Dentro das competências específicas de Ciências da Natureza para o Ensino Fundamental (BNCC, Ensino Fundamental, p. 324), destacam-se as seguintes:

Analisar, compreender e explicar características, fenômenos e processos relativos ao mundo natural, social e tecnológico (incluindo o digital), como também as relações que se estabelecem entre eles, exercitando a curiosidade para fazer perguntas, buscar respostas e criar soluções (inclusive tecnológicas) com base nos conhecimentos das Ciências da Natureza.

Utilizar diferentes linguagens e tecnologias digitais de informação e comunicação para se comunicar, acessar e disseminar informações, produzir conhecimentos e resolver problemas das Ciências da Natureza de forma crítica, significativa, reflexiva e ética. (grifos nossos) por fazerem referência ao Pensamento Computacional, ou a algum termo a ele relacionado e/ou às tecnologias digitais. Dentre as habilidades relativas aos Anos Iniciais do Ensino Fundamental, apenas uma refere-se à tecnologia, mas de forma bastante significativa, por enfatizar o processo criativo:

(EF05CI05) Construir propostas coletivas para um consumo mais consciente e criar soluções tecnológicas para o descarte adequado e a reutilização ou reciclagem de materiais consumidos na escola e/ou na vida cotidiana. (BNCC, Ensino Fundamental, p. 341).

Finalmente, na área das Ciências Humanas, há uma das competências específicas referindo-se às tecnologias digitais (competência específica 7). A Figura 7 apresenta as habilidades, por componentes, desta área:

Figura 1 - Tecnologias digitais na área das Ciências Humanas

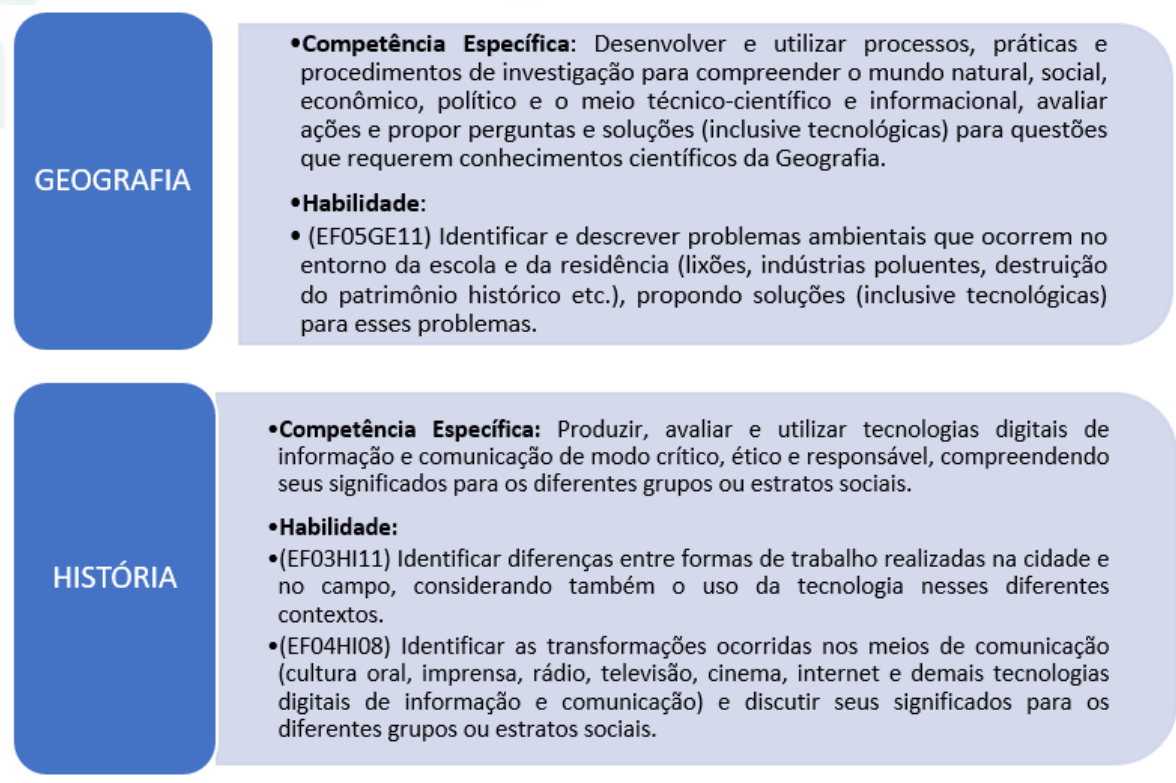

Fonte: Elaborada pelo pesquisador. 


\section{O impacto da BNCC na formação dos professores para a Educação Básica: a Resolução CNE/CP n 2} /2019

A Resolução $n^{\circ} 2$ do Conselho Pleno do Conselho Nacional de Educação, de 20 de dezembro de 2019, traça as diretrizes que devem nortear os currículos para a formação de professores em nível superior para todas as etapas da Educação Básica, substituindo resolução anterior, do ano de $2015^{4}$. A análise comparativa dos documentos permitirá a constatação de uma mudança nos objetivos a serem focados na formação de professores a partir do ano de 2020. A ideia central da Resolução 02/2019 é garantir que os cursos formem profissionais capacitados para a aplicação da Base Nacional Comum Curricular, utilizando como alicerce o mesmo princípio de desenvolvimento das habilidades e competências, gerais e específicas. Para as licenciaturas, elas estão organizadas a partir de três grupos principais, que envolvem o conhecimento, a prática e o engajamento profissional.

Após os primeiros artigos destinados às definições gerais, a Resolução 02/2019, a partir do capítulo III, trata da forma como se deverá organizar o currículo nos cursos de formação inicial de professores para a Educação Básica. Além de reconhecer o valor da educação e o direito dos estudantes ao ensino de qualidade, consonante com o artigo n 205 da Constituição Federal, em seu artigo $7^{\circ}$, parágrafo II, a resolução define a necessidade de introduzir discussões sobre a teoria e a prática docente já nos primeiros momentos do ensino superior. Soma-se a isso o parágrafo VIII, que ressalta a centralidade da prática por meio de estágios, reconhecendo a necessidade de um incessante diálogo entre as instituições de Educação Básica e os cursos de formação de professores, nesse ponto mantendo aspectos da Resolução CNE/CP nº 2/2015.

Apesar das permanências, as alterações em aspectos centrais apontam para grandes desafios para sua implementação. Sem receber o mesmo alarde da Medida Provisória $n^{\circ}$ 746/2016, que instituiu a Reforma do Ensino Médio, a Resolução define a aplicação da BNCFormação, o que implica em uma ampla reforma no currículo da formação de professores. Enquanto uma análise da Resolução 02/2015 revela um enfoque na "interdisciplinaridade", palavra que aparece nada menos do que 22 vezes no documento; na Resolução 02/2019 ela está presente apenas 3 vezes. Já o termo "habilidades" surge 23 vezes e "competências", 50 vezes. Em síntese, há uma mudança expressiva naquilo que deve compor um professor preparado para atuar na Educação Básica. Tal enfoque aparece explicitamente citado nos artigos $2^{\circ}$ e $3^{\circ}$ da Resolução de 2019 da seguinte forma:

Art. $2^{\circ} \mathrm{A}$ formação docente pressupõe o desenvolvimento, pelo licenciando, das competências gerais previstas na BNCC-Educação Básica, bem como das aprendizagens essenciais a serem garantidas aos estudantes, quanto aos aspectos intelectual, físico, cultural, social e emocional de sua formação, tendo como perspectiva o desenvolvimento pleno das pessoas, visando à Educação Integral.

Art. $3^{\circ}$ Com base nos mesmos princípios das competências gerais estabelecidas pela BNCC, é requerido do licenciando o desenvolvimento das correspondentes competências gerais docentes. 
Embora a BNCC busque atender às demandas da Educação Básica, recebendo atenção especial para sua implementação, que conta com a produção de um amplo material de campanha que enfoca o esclarecimento e a preparação dos professores já formados e atuantes nessa área, a Resolução 02/2019 acaba por implantar uma reforma análoga nos cursos de licenciatura de todo o país, uma vez que alinha a formação de professores com o princípio de desenvolvimento de habilidades e competências, sem, contudo, receber o mesmo aporte para tal.

Outro ponto que reforça a necessidade de reorganização significativa dos currículos está na distribuição da carga horária, já que essa Resolução estipula um efetivo de 3200 horas para cursos de licenciatura, distribuídas em três grupos: Grupo 1 (800 horas), Grupo 2 (1.600 horas) e Grupo 3 (800 horas).

A maior carga horária (Grupo 2) é destinada ao domínio dos objetos do conhecimento específicos da área. Contudo, cabe ressaltar que o inciso II do artigo no 11 destaca que "o domínio pedagógico desses conteúdos" deve ser contemplado por esse segmento, abrindo campo para a questão da didática específica do campo do conhecimento cursado pelo licenciando. Merece atenção ainda o fato de que tais conteúdos deverão ser ministrados entre o $2^{\circ}$ e o $4^{\circ}$ ano do curso de licenciatura.

As 800 horas do Grupo 1 se dedicarão ao estudo e à apropriação da BNCC e aos conhecimentos relacionados com a didática e seus fundamentos, com enfoque na realidade das escolas e de seus estudantes, devendo ser aplicadas já no primeiro ano do curso. Em tese, um estudante universitário que optar pelo curso de licenciatura em Matemática, por exemplo, terá um primeiro contato com o campo da Pedagogia para depois iniciar os estudos específicos de seu curso. Cabe destaque para a compreensão dos fenômenos digitais e o Pensamento Computacional, que passam a compor o currículo geral das licenciaturas 5 .

Por fim, no Grupo 3 está a dimensão prática que deve ser adotada pelos cursos de licenciatura, sendo estas 400 horas de estágio supervisionado em situação real de trabalho e o restante para a prática dos componentes curriculares dos Grupos I e II.

Quando se compara com a Resolução CNE/CP n 2/2015, nota-se uma mudança significativa na distribuição da carga horária, mantidas as mesmas 3200 horas totais. O Art. 13, da Resolução de 2015, dividia o tempo formativo em 4 etapas, sendo 400 horas de prática, 400 horas de estágio supervisionado, 200 horas de aprofundamento em horas específicas de interesse do estudante por meio de iniciação científica, iniciação à docência, extensão, monitoria, dentre outras, e 2.200 horas de atividades formativas relacionadas com o núcleo específico da formação, atentando no inciso 2 para a necessidade de favorecimento da interdisciplinaridade. Chama atenção a redução em 600 horas neste último ponto, quando constituída a Resolução 02/2019, sendo agora destinadas para BNCC e estudos no campo da Pedagogia. No caso dos educadores multidisciplinares da Educação Infantil, deverão ser levadas em consideração a especificidade das escolas, incluindo suas rotinas, o processo de aprendizagem da criança em cada uma das faixas etárias contempladas por este segmento, os 
direitos de aprendizagem e desenvolvimento da BNCC, tais como conviver, brincar, participar, explorar, expressar, conhecer-se, atendendo aos objetivos de desenvolvimento e aprendizagem da BNCC, enfatizando ainda mais a questão das competências e habilidades nesse segmento específico.

Poder-se-ia levantar ainda a questão de que a BNCC é um documento complexo e extremamente recente. Com isso, mesmo em nível superior, não é exagerado supor que os docentes terão dificuldades para adequar-se a essa nova realidade proposta e colocá-la em prática nos cursos de licenciatura. No que diz respeito aos Anos Iniciais do Ensino Fundamental e na Educação Infantil, as mudanças são ainda mais marcantes.

Ainda nesta Resolução tem-se, no capítulo IV, explícita referência ao Pensamento Computacional e à necessidade de que os licenciandos vivenciem experiências durante o processo de formação inicial que Ihes permita ter uma "compreensão básica dos fenômenos digitais e do Pensamento Computacional, bem como de suas implicações nos processos de ensino-aprendizagem na contemporaneidade." (RESOLUÇÃO CNE/CP n 2/2019).

Diante do exposto, percebe-se que a formação do professor para a Educação Básica sofrerá profundas transformações. Está-se diante de uma mudança de paradigmas e, evidentemente, um novo objeto de estudos e pesquisa se abre, desafiando a comunidade científica a estudálo profundamente. Cabe, porém, mais uma vez ressaltar o fato de que, a partir de agora, o professor precisará ser formado a partir das competências e habilidades estabelecidas na Base Nacional Comum Curricular e nela são feitas referências diretas e explícitas ao Pensamento Computacional e ao uso das tecnologias digitais.

\section{Resultados empíricos e as primeiras análises}

Se o Pensamento Computacional e as tecnologias digitais estão presentes na Base Nacional Comum Curricular e esta constitui-se em um referência para a construção dos currículos de formação de professores para a Educação Básica, então é fundamental que esses professores, em seu processo formativo, possam vivenciar experiências que lhes permitam desenvolver as competências e habilidades relacionadas a tais elementos.

A partir desta perspectiva, propôs-se realizar uma intervenção junto a um grupo de licenciandos em Pedagogia da Universidade do Vale do Itajaí, a fim de evidenciar a percepção por parte desses acadêmicos dos pilares do Pensamento Computacional. Esta intervenção foi desenvolvida por meio de cinco oficinas pedagógicas, concebidas a partir de um enfoque construcionista, utilizando-se diferentes estratégias para inserção do Pensamento Computacional: computação desplugada, brinquedos programáveis, atividades lúdicas, uso de softwares e programação. Os dados obtidos foram analisados por meio de análise de conteúdo, com categorias definidas a priori. As categorias constituem-se nos próprios pilares do Pensamento Computacional. Neste momento, apresentar-se-ão as evidências coletadas acerca do pilar "identificação de padrões". 
Após jogar algumas partidas do Jogo das Tampinhas, MJDS ${ }^{6}$ percebeu que a vitória no jogo dependia de restarem quatro tampinhas de mesma cor na última jogada. E sempre que isto acontecia, ela vencia. Diante desta constatação, realizava as jogadas de forma a deixar, na última rodada, quatro tampinhas de mesma cor:

Pesquisador: $O$ que tu percebeste do jogo, assim??

MJDS: Primeiro eu percebi que todas as vezes que eu ficava com 4 tampinhas, toda vida que sobrava 4 tampinhas, eu sempre ganhava. Aí eu sempre contava pra sobrar 4 . 6

Isto acontece porque, sendo doze o número de tampinhas brancas (por exemplo) e uma verde, pode-se dividir doze em grupos de quatro, formando exatamente três grupos, sem deixar resto. Como cada jogador pode retirar uma, duas ou três tampinhas de cada vez, o segundo jogador pode sempre completar um grupo de quatro tampinhas, de tal forma que na última jogada restem quatro tampinhas brancas e a tampinha verde. Como o primeiro jogador pode retirar, no máximo, três tampinhas brancas, restará pelo menos uma tampinha branca para ser retirada pelo segundo jogador e, ao primeiro jogador, caberá comprar a tampinha verde, o que implica em sua derrota. Ainda durante a realização do Jogo das Tampinhas, o pesquisador modificou o número de tampinhas. Além disso, alterou também o número de tampinhas que poderiam ser retiradas: uma, duas, três ou quatro. Ao jogar com um dos participantes no quadro (as tampinhas foram substituídas por círculos), a quantidade de círculos retirada por eles ia sendo registrada na lousa, formando uma tabela, como a representada a seguir (Tabela 1):

Tabela 1 - Jogo das Tampinhas

\begin{tabular}{l|l}
\hline JOGADOR 18 $^{8}$ & JOGADOR 2 \\
\hline 4 & 1 \\
1 & 4 \\
3 & 2 \\
2 & 3
\end{tabular}

Fonte: Elaborada pelo Pesquisador.

Ao serem questionados sobre o padrão que está escondido na tabela e que precisa ser descoberto, eles o identificaram, ao constatarem que a soma em cada uma das jogadas deve ser igual a cinco, conforme se pode perceber pelo diálogo que segue:

Pesquisador: Ela tira 2 e eu tiro 3. E ela perde o jogo. Agora observem o que há em comum em todas as jogadas que nós fizemos.

Vários: Todas formaram $5 .{ }^{9} \leftarrow$

Pesquisador: Quando eu disse assim para a JMG: "você só pode tirar 1, 2, 3 ou 4 tampinhas", que decisão vai estar na minha mão?

IMDO: Completar 5.

Pesquisador: Eu poder completar...

Vários: 5! 
Em outro momento, quando colocados diante das sequências numéricas (mostradas na Figura 2), os participantes não apresentaram maiores dificuldades para identificar o padrão presente em cada uma delas e descrevê-lo.

Figura 2 - Sequências numéricas

$\begin{array}{cccc}1 & 2 & 1 & 1 \\ 2 & 4 & 2 & 2 \\ 3 & 6 & 3 & 4 \\ 4 & 8 & 4 & 8 \\ 5 & 10 & 5 & 16 \\ \vdots & 12 & \vdots & \vdots \\ 9 & \vdots & & \square 1\end{array}$

Fonte: Elaborada pelo Pesquisador.

Pesquisador: Como é que eu poderia descrever esta sequência?

SRL: Múltiplos de 2.

Pesquisador: Múltiplos de 2. Poderia. E esta daqui?

SRL: Sequência de unidades.

JDC: Vai acrescentando 1.

Pesquisador: Poderia, poderia. E essa daqui? Qual vai ser o próximo termo?

JDC: 32.

Pesquisador: 32, por quê?

JDC: Porque tá sempre multiplicando por 2.

Ao iniciarem a atividade de construção de polígonos, a primeira construção realizada foi a de um triângulo. Depois de aprenderem como medir os ângulos internos de um polígono utilizando o Geogebra ${ }^{10}$, eles utilizaram uma variável para guardar a soma destes ângulos internos. Ao movimentarem um dos vértices do triângulo, eles perceberam que os outros dois ângulos do triângulo sofriam alterações em seus valores, mas o valor de permanecia constante, qualquer que fosse o movimento realizado e o triângulo construído. Assim, concluíram que a soma dos ângulos internos de um triângulo é sempre igual a $180^{\circ}$.

Pesquisador: Quando eu mudo um deles, os outros dois mudam?

Vários: Sim.

Pesquisador: $\mathrm{O}$ que não está mudando aqui

Vários: A soma.

Pesquisador: Vocês percebem que qualquer que seja o triângulo que eu estou montando a soma dos ângulos internos está dando sempre...

MJDS: $180^{\circ}$. 
Ainda nesta atividade aconteceu algo que não havia sido previamente pensado pelo pesquisador e que merece destaque, porque evidencia o potencial deste tipo de atividade para desenvolver esta característica do Pensamento Computacional. Num dado momento, SRL percebeu algo muito interessante: ao movimentar um determinado vértice do quadrilátero, o ângulo oposto ao vértice movimentado não sofria alteração, enquanto os outros dois ângulos internos variavam.

Pesquisador: Será que isto que alguns já verificaram vale para todos os polígonos de quatro lados? A gente pode fazer um teste. Vocês podem movimentar um vértice qualquer e mudar o cara de lugar. Quando eu mudo um vértice de lugar, os outros ângulos mudam?

IRC: Só o alfa.

Pesquisador: Olha só que interessante! Quando eu mudo este vértice aqui de lugar...

PFMB: Muda os números.

Pesquisador: Todos os outros ângulos mudam?

SRL: Menos o que forma o que forma o triângulo, o terceiro ponto.

Pesquisador: Qual o ângulo que não muda?

MJDS: Eu esqueci o nome...

JDC: O oposto.

A Figura 3 ilustra a situação descrita anteriormente. O ângulo alfa (), oposto ao vértice A, não sofre variação à medida que o vértice é deslocado. Note-se que o vértice $A$ assume quatro posições distintas, mas, no caso em questão, o valor do ângulo alfa manteve-se constante.

Figura 3 - Invariabilidade do ângulo oposto

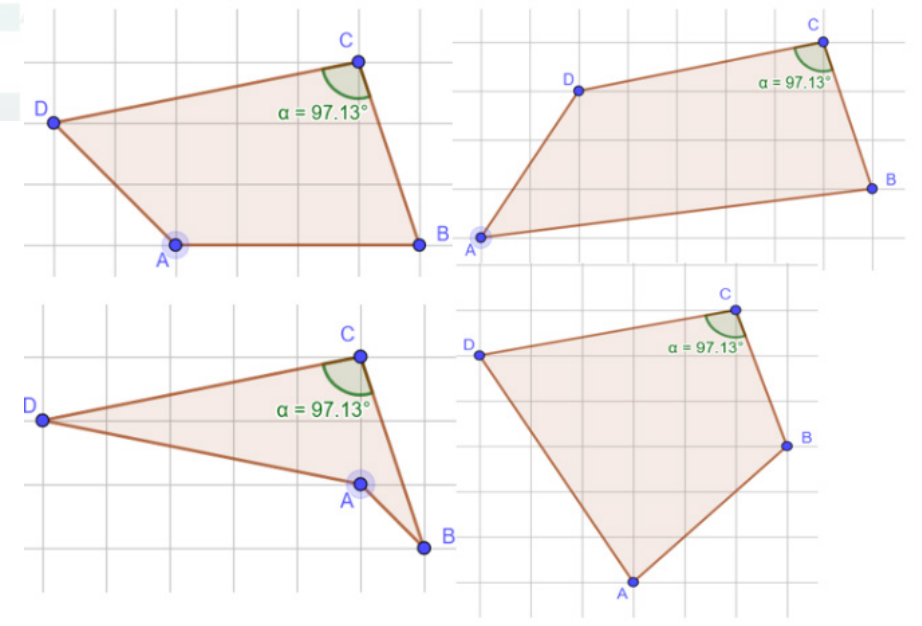

Fonte: Detalhes de print screen do software Geogebra.

Em outro momento, enquanto investigavam a relação entre o número de lados de um polígono e a soma dos seus ângulos internos, a partir de uma tabela semelhante à mostrada na Figura 4, os participantes (agora a maior parte deles, diferentemente do que aconteceu no Jogo das Estacas) conseguiram construir um algoritmo que permitisse calcular a soma dos ângulos internos de um polígono a partir da quantidade de lados, desde que se conhecesse a 
soma dos ângulos internos do polígono "anterior" a ele.

Figura 4 - Soma dos ângulos internos de um polígono em função do número de lados

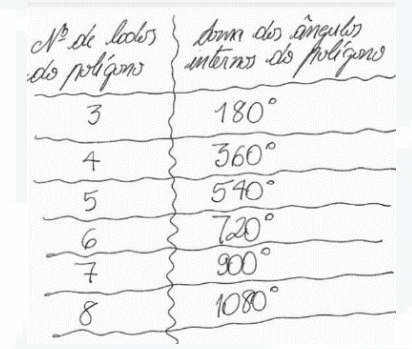

Fonte: Elaborada pelo pesquisador.

Quando organizados desta forma, os participantes conseguiram identificar o seguinte padrão: à medida que o número de lados aumenta em uma unidade, a soma dos ângulos internos aumenta em $180^{\circ}$ ", conforme evidenciado pelo diálogo que segue:

Pesquisador: [...] Vai conseguir responder a esta pergunta quem ao longo da atividade sacou um padrão, porque tem uma lógica, não é aleatório. Seja o que Deus quiser? Não! Tem uma lógica! A pergunta é: qual é esta lógica? Quem consegue descrevê-la para mim?

MJDS: Eu.

Vários: Ai...

MJDS: Sempre vai somando 180.

Pesquisador: Como assim?

MJDS: A cada número de lados que aumenta, aumenta também a soma dos ângulos internos. É sempre 180 a mais.

Pesquisador: Vamos ver se isso é verdade. De três para quatro aumentou quanto?

Vários: 180.

Pesquisador: De quatro para cinco?

Vários: 180.

Pesquisador: Aumentou $180^{\circ}$. De cinco para seis?

Vários: 180.

Pesquisador: De seis para sete?

Vários: 180.

Pesquisador: Existe, claramente, um...

Vários: Padrão.

Embora tendo percebido a existência deste padrão, o que já seria suficiente para fins de adequação ao objetivo desta pesquisa, procurou-se ir um pouco mais além, mostrando para eles que, embora o que observaram se constituísse efetivamente em um padrão, ele ainda nos tornava reféns de um elemento anterior, ou seja, para descobrir a soma dos ângulos internos 
de um polígono com 13 (treze) lados, seria necessário saber a soma dos ângulos internos de um polígono com 12 (doze) lados e, para este, precisaria se conhecer a soma dos ângulos internos de um polígono com 11 (onze) lados e assim sucessivamente, constituindo uma sequência recursiva ${ }^{11}$. Desta forma o padrão, embora verdadeiro, não seria muito útil. Para auxiliar na busca deste novo padrão, o pesquisador reescreveu a tabela no quadro, organizando os dados de uma maneira diferente, conforme pode ser verificado a seguir, na Figura 5:

Figura 5 - Soma dos ângulos internos de um polígono em função do número de lados: outra representação

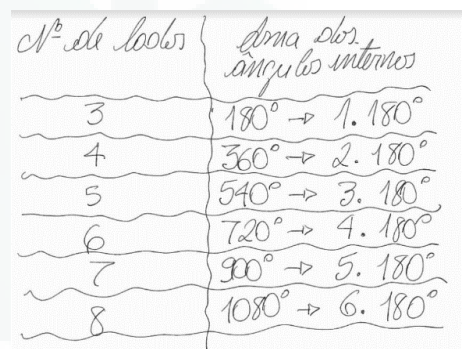

Fonte: Elaborada pelo Pesquisador.

Ao pedir para que os participantes comparassem a quantidade de vezes que o fator $180^{\circ}$ aparecia na segunda coluna da tabela com a quantidade de lados do polígono, o novo padrão foi identificado por grande parte dos participantes, conforme pode ser percebido a partir do diálogo a seguir:

Pesquisador: $O$ que eu gostaria que vocês entendessem é o seguinte: que para eu saber quantas vezes o 180 aparece na soma dos ângulos internos, basta eu pegar o...

Vários: Número de lados da figura $\leftarrow$

Pesquisador: E subtrair...

Vários: Dois

Pesquisador: Então, pensa comigo. Aquela figura que tem 30 lados...

BDSM: Subtrair dois?

Pesquisador: Subtrair dois, porque olha só: quando a figura tinha dois lados, quantas vezes aparecia o 180? Uma só! 3 menos 2 igual a 1. Quando a figura tinha quatro lados, aparecia duas vezes o 180: quatro menos dois igual a 2. Quando a figura tinha cinco lados aparecia três vezes o 180: cinco menos dois igual a 3. Seis menos dois, quatro. Sete menos dois, cinco. Então, se a figura tem vinte e cinco lados, quantas vezes vai aparecer o 180 ?

Vários: 23

Pesquisador: Então, para eu saber a soma dos ângulos internos da figura que tem 25 lados, basta eu fazer 23 vezes. $\leftarrow$

Vários: 180. 
IRC: Ãnnn.

Pesquisador: E o que é esse 23 aqui?

JDC: É o número de lados menos dois.

Pesquisador: É o número de lados menos dois. Qual a vantagem disso em relação à tabela?

JDC: Total. Serve para qualquer um.

Pesquisador: E se a figura tiver 50 lados?

JDC e SRL: Terá 48 vezes o 180.

Pesquisador: A soma dos ângulos internos vai ser?

SRL: 48 vezes 180.

Pesquisador: De onde veio este 48 ?

(????): Do número de lados menos dois.

\section{Considerações}

As tecnologias digitais estão impactando a forma como nossa sociedade vem se organizando nas suas mais diversas instâncias, modificando a forma como acessamos informações, desenvolvemos pesquisas, realizamos transações econômicas e afetando de forma marcante a forma pela qual nos relacionamos (VALENTE, 2016). Entretanto, estas tecnologias não têm sido utilizadas, em geral, para desenvolver a criatividade e o pensamento dos sujeitos envolvidos nesses processos (BUCKINGHAM, 2007). Diante deste quadro de subutilização das tecnologias digitais, muitos países têm buscado alterar seus currículos, buscando inserir conceitos de Ciência da Computação nos diversos níveis que compõem sua estrutura escolar, desde os Anos Iniciais da escolarização, uns por meio de criação de disciplinas específicas para tratar o assunto, outros por meio de uma perspectiva de transversalidade. Essas alterações curriculares visam desenvolver a programação e o Pensamento Computacional.

A Base Nacional Comum Curricular inclui o uso criativo e crítico das tecnologias digitais e o Pensamento Computacional no conjunto de competências e no de habilidades a serem desenvolvidos pelos estudantes ao longo da Educação Básica. Mas, para que isso ocorra, é imprescindível que os professores estejam preparados para construir situações de aprendizagens que permitam aos estudantes desenvolvê-las. Neste sentido, eles mesmos precisam vivenciar experiências para que possam desenvolver tais competências e habilidades.

A análise dos dados obtidos na parte empírica da pesquisa em curso evidenciou ser possível e viável a inserção de atividades pedagógicas com intuito de desenvolver o Pensamento Computacional em licenciandos em Pedagogia. Particularmente, nas situações descritas neste artigo, estas atividades contribuíram para que os participantes da pesquisa reconhecessem 
padrões em diferentes contextos, tais como jogos, sequências numéricas e geometria e, com isso, abriram possibilidade para o desenvolvimento do Pensamento Computacional nestes sujeitos.

\section{Referências}

BARCELOS, Thiago Schumacher; SILVEIRA, Ismar Frango. Pensamento computacional e educação matemática: Relações para o ensino de computação na educação básica. In: XX Workshop sobre Educação em Computação, Curitiba. Anais do XXXII CSBC. 2012. p. 23.

BBC (United Kingdon). Bitesize - Introduction to computational thinking. Disponível em: <https://www.bbc.com/bitesize/guides/zp92mp3/revision/1 >. Acesso em: 10 jan. 2020.

BLIKSTEIN, P. O pensamento computacional e a reinvenção do computador na educação, 2008. Disponível em: http://www.blikstein.com/paulo/documents/online/ol_ pensamento_ computacional.html. Acesso em: 21/04/2018

BRACKMANN, C. P. Desenvolvimento do pensamento computacional através de atividades desplugadas na educação básica. Tese de Doutorado. Universidade Federal do Rio Grande do Sul, 2017, $221 f$.

BRASIL, MEC. Base Nacional Comum Curricular: BNCC. Disponível em: http:// basenacionalcomum.mec.gov.br/wp-content/uploads/2018/04/BNCC_19mar 2018_ versaofinal.pdf. Acesso em: 29/05/2018.

Resolução CNE/CP 2/2015. Diário Oficial da União, Brasília, 14 de julho de 2010.

Resolução CNE/CP 2/2019. Diário Oficial da União, Brasília, 20 de dezembro de 2019.

BRITISH, B. C. Introduction to computational thinking. Disponível em: https://www.bbc. co.uk/bitesize/guides/zp92mp3/revision/1. Acesso em: 01/03/2020.

BUNDY, A. Computational thinking is pervasive. Journal of Scientific and Practical Computing, 1:67-69, 2007.

CIEB, Centro de Inovação para a Educação Brasileira. CIEB NOTAS TÉCNICAS \#12 CONCEITOS E CONTEÚdOS DE INOVAÇÃO E TECNOLOGIA (I\&T) NA BNCC, 2018, p.12. Disponível em: http://www.cieb.net.br/wp-content/uploads/2018/04/CIEB-Notas-12-Conceitos-eConte\%C3\%BAdos-de-Inova\%C3\%A7\%C3\%A3o-e-Tecnologia -na-BNCC.pdf. Acesso em: $15 / 05 / 2018$.

CSTA, Computer Science Teacher Association. "K-12 Computer Science Standards - Revised 2011- The CSTA Standards Task Force," Association for Computing Machinery, 2011

LIUKAS, L. Hello Ruby: adventures in coding. Feiwel \& Friends, 2015.

MESTRE, P.; ANDRADE, W.; GUERRERO, D.; SAMPAIO, L.; DA SILVA RODRIGUES, R.; COSTA, E. Pensamento Computacional: Um estudo empírico sobre as questões de matemática do PISA. In: Anais dos Workshops do Congresso Brasileiro de Informática na Educação. 2015. p. 1281.

OBAMA, B. Discurso à nação. 2013. Disponível em: https://www.youtube.com/ watch?v=6XvmhE1J9PY (Acesso: 08/05/2018) 
PAPERT, S. A máquina das crianças: Repensando a escola na era da informática. Artes Médicas: Porto Alegre, 1994.

RAABE, A.; VIEIRA, M.V; SANTANA, A.M.; GONÇALVES, F.; BATHKE, J. Recomendações para - Pensamento Computacional na Educação Básica. $4^{\circ}$ DesaflE - Workshop de Desafios da Computação Aplicada à Educação. Recife, PE, 2015. Disponível em: https://www. researchgate.net/publication/327273816_Recomendacoes_para_Introducao_do_Pensamento_ Computacional_na_Educacao_Basica. Acesso: 28/01/2020.

Royal Society (2012) "Shut down or restart? The way forward for computing in UK schools". London: The Royal Society. Disponível em: https://royalsociety.org/ /media/education/ computing-in-schools/2012-01-12-computing-in-schools.pdf. Acesso em: 26 fev. 2020.

SELBYC; WOOLLARD, J. Computational thinking: the developing definition. Disponível em: http://eprints.soton.ac.uk/356481/. Acesso em: 15/05/2018.

The Royal Society (2012) "Shut down or restart? The way forward for computing in UK schools". London: The Royal Society. Disponível em: https://royalsociety.org/ /media/ education/computing-in-schools/2012-01-12-computing-in-schools.pdf. Acesso em: 26/02/2020.

VALENTE, J.A. Integração do pensamento computacional no currículo da educação básica: diferentes estratégias usadas e questões de formação de professores e avaliação do aluno. Revista e-Curriculum, São Paulo, v.14, n.03, p. 864 - 897 jul./set.2016 e-ISSN: 1809-3876 Programa de Pós-graduação Educação: Currículo - PUC/SP http://revistas.pucsp.br/index.php/ curriculum. Acesso: 01/05/2018

WING, J. M. Computational thinking. Communications of the ACM, v. 49, n. 3, p. 33, 2006

YADAV, A. L. Introducing Computational Thinking in Education Courses. SIGCSE11. Dallas, USA: ACM. (2011)

1 Tecnologias Digitais de Informação e Comunicação

2 O desenvolvimento de conceitos da Ciência da Computação e, particularmente, do Pensamento Computacional sem o uso de computadores é denominado Computação Desplugada.

3 Ao longo do texto da BNCC/EF há, para o componente Língua Portuguesa, mais de 50 referências a termos associados ao Pensamento Computacional.

4 Quando, no texto, se fizer referência à Resolução de 2015, trata-se da Resolução nº 02/2015, do Conselho Nacional de Educação - CNE.

5 Ver Art. $2^{\circ}$, parágrafo II, letra f. 
6 Código para individualização dos sujeitos da pesquisa.

7 As transcrições correspondem, sempre que possível, às falas dos sujeitos, sem correções.

$8 \quad 0$ jogador 1 é aquele que inicia o jogo.

9 Como já ressaltado, os pilares do Pensamento Computacional estão conectados entre si. Em função disso, a presença de um deles é precedida e antecedida por outros. Neste caso, o uso do "todas" pressupõem a passagem pelas "unidades", ou seja, pela $1^{\text {a }}$ jogada, pela $2^{\mathrm{a}}$, pela $3^{\mathrm{a}}$ e $4^{\mathrm{a}}$ jogadas, o que implica na aceitação de que houve previamente uma decomposição.

10 Software de geometria dinâmica.

11 Simplificadamente, pode-se dizer que uma sequência é recursiva quando, para se determinar um de seus elementos, é necessário conhecer um ou mais elementos que o antecedem. 